\section{International Scientific Journal Theoretical \& Applied Science}

p-ISSN: 2308-4944 (print) e-ISSN: 2409-0085 (online)

Year: $2018 \quad$ Issue: $01 \quad$ Volume: 57

Published: $30.01 .2018 \quad$ http://T-Science.org

SECTION 9. Chemistry and chemical technology.
Igor Viktorovich Goloperov

Candidate of chemical sciences, Docent, Department of Occupational Health and Environmental

Safety, Ukrainian Engineering and Pedagogical Academy, Ukraine goloperov_igor_2018@ukr.net

Elena Aleksandrovna Belova Candidate of chemical sciences, Docent, Department of Occupational Health and Environmental

Safety, Ukrainian Engineering and Pedagogical Academy, Ukraine belovaalena@ukr.net

Larisa Vladimirovna Baklanova Candidate of chemical sciences, Docent, Head of the Department of Occupational Health and Environmental Safety, Ukrainian Engineering and Pedagogical Academy, Ukraine baklanovalarisa@ukr.net

Aleksandr Nikolaevich Baklanov Doctor of chemical sciences, Professor, Head of the Department of Occupational Health and Environmental Safety, Ukrainian Engineering and Pedagogical Academy, Ukraine baklanov_oleksandr@meta.ua

\title{
IMPROVING FOOD SAFETY - INCREASE OF EXPRESSIVE ANALYSIS TO TOXIC ELEMENTS
}

\footnotetext{
Abstract: A solution to the problem of food safety is proposed by increasing the expressiveness of their analysis for the content of toxic elements. The use of joint action of ultrasound of high and low frequencies for the intensification of the processes of wet mineralization of various food products has been studied. It is shown that the use of combined action of high and low frequency ultrasound makes it possible, in comparison with using only lowfrequency ultrasound, to increase the extraction rate, to use one oxidizer for all food products, which makes it possible to create a unified method for analyzing various food products.

Key words: ultrasound, food products, safety, toxic elements, mineralization.

Language: Russian

Citation: Goloperov IV, Belova EA, Baklanova LV, Baklanov AN (2018) IMPROVING FOOD SAFETY INCREASE OF EXPRESSIVE ANALYSIS TO TOXIC ELEMENTS. ISJ Theoretical \& Applied Science, 01 (57): 260-265.

Soi: http://s-o-i.org/1.1/TAS-01-57-42 Doi: crossef https://dx.doi.org/10.15863/TAS.2018.01.57.42

\section{ПОВЫШЕНИЕ БЕЗОПАСНОСТИ ПИЩЕВЫХ ПРОДУКТОВ - ПОВЫШЕНИЕ ЭКСПРЕССНОСТИ АНАЛИЗА НА ТОКСИЧНЫЕ ЭЛЕМЕНТЫ}

Аннотация: Предложено решение проблемы безопасности использования пищевых продуктов путем повышения экспресности их анализа на содержание токсичных элементов. Изучено использование совместного действия ультразвука высокой и низкой частот для интенсификации процессов мокрой минерализачии различных пищевых продуктов. Показано, что использование совместного действия ультразвука высокой и низкой частот позволяет, по сравнению с использованием только низкочастотного ультразвука, повысить степень извлечения, использовать один окислитель для всех пищевых продуктов, что позволяет создать унифицированную методику анализа различных пищевых продуктов.

Ключевые слова: ультразвук, пищевые продукты, безопасность, токсичные элементы, минерализация.
} 


\section{Введение.}

Существующие в СНГ стандартные методики анализа длительны из-за длительности стадии минерализации, занимающей от 3 до 40 часов в зависимости от вида пищевого продукта. Для интенсификации минерализации наибольшее распространение получило микроволновое излучение. Однако, микроволновые печи отличаются высокой стоимостью, более 5 тыс. долларов США. В связи с чем, нами использован ультразвук (УЗ) для интенсификации минерализации как сухим, так и мокрым способами [1-4].

Для интенсификации сухой минерализации УЗ использовался только для создания эффекта кипящего слоя, благодаря чему, каждая частичка карбонизата пищевого продукта подвергалась воздействию окислителей в парообразной форме. В связи с чем, экспрессность анализа была повышена в 10-12 раз по сравнению с классическим вариантом сухой минерализации $[2,3]$.

Более эффективно использование УЗ для интенсификации мокрой минерализации [1]. Изучено использование УЗ частотой от 18 до 100 МГц. При этом время минерализации сократилось в 10-20 раз в зависимости от вида пищевого продукта, а степень извлечения свинца и кадмия составила 94-98 \% [1].

Описано использование совместного действия УЗ высокой и низкой частот для интенсификации кислотной экстракции свинца и кадмия из жиров и масел. Было показано, что применение совместного действия УЗ высокой и низкой частот позволяет повысить снизить энергоемкость анализа за счет снижения интенсивности УЗ и улучшить метрологические характеристики результатов анализа [5]. Также было изучено использование совместного действия УЗ высокой и низкой частот для интенсификации пробоподготовки при анализе сахара и продуктов на его основе на содержание свинца, меди и кадмия. При этом, УЗ был использован для перевода соединений свинца, меди и кадмия в кинетически лабильные. В связи с чем, возможна их количественная экстракция в виде диэтилдитиокарбаматов в хлороформ из растворов сахара концентрацией до 100 г/л [4].

Предлагаемая работа посвящена изучению совместного действия УЗ высокой и низкой частот для интенсификации процессов мокрой минерализации пищевых продуктов.

Экспериментальная часть. Для создания низкочастотных колебаний использовали трубчатые магнитострикционные излучатели, в которые устанавливали пробирку с исследуемым раствором. На верхнюю часть пробирки одевали, с использованием фторопластовых уплотнителей, кольцеобразный пьезоэлектрический излучатель (с рабочей частотой 1 или 2 МГц) типа ЦТС-19, изготовленный из цирконата титана-свинца. Магнитострикционный излучатель присоединяли к модернизированному ультразвуковому диспергатору УЗДН-1М, что позволяло создавать в изучаемых растворах ультразвуковые колебания частотой от 18 до 44 кГц с интенсивностью от 0,05 до 15 Вт/см ${ }^{2}$ (ограничивалась прочностью пробирки). Питание пьезоэлектрического излучателя осуществляли от лампового генератора типа 24-УЗГИ-К-1,2, что позволяло создавать в изучаемых растворах ультразвуковые колебания частотой 1 или 2 МГц с интенсивностью до $12 \mathrm{BT} / \mathrm{cm}^{2}$ (ограничивалась прочностью излучателя) [4].

Методика проведения эксперимента при анализе мяса (свинина постная, говядина нежирная) соков, фруктов муки, кофе и овощей. 4 мл сока или 0,50 г муки, кофе, овощей, фруктов, мяса помещали в пробирку. Приливали смесь (1 : 1) $\mathrm{H}_{2} \mathrm{O}_{2}+\mathrm{HNO}_{3}$ ( 8 мл при анализе соков и 10 мл при анализе овощей, кофе или муки).

Методика проведения эксперимента при анализе пива и круп. 4 мл пива или 0,5 г размолотых круп помещали в пробирку. Приливали 10 мл смеси пероксида водорода и азотной кислоты в соотношении $(1: 1)$.

Методика проведения эксперимента при анализе молокопродуктов. Навеску продукта массой 2,00 г (при анализе молока, сливок $8 \%$ и кисломолочных продуктов) или 1,00 г (при анализе творога, сухого и сгущённого молока, масла сливочного, сливок жирностью более 8\%) помещали в пробирку и приливали в первом случае 3 мл азотной кислоты (1:1); во втором - 3 мл смеси азотной $(1: 1)$ и соляной $(1: 1)$ в соотношении (3:1).

Методика проведения эксперимента при анализе хлебопродуктов. При анализе сахаросодержащих хлебопродуктов (сдоба донецкая, булочка с повидлом), навеску продукта массой 1,00 г помещали в пробирку и приливали 6 мл смеси азотной кислоты с перекисью водорода в соотношении (1:1), а при анализе хлеба - 6 мл азотной кислоты (1:1). К полученному минерализату приливали и приливают 1 мл 0,001 мг/л раствора $\mathrm{Pd}\left(\mathrm{NO}_{3}\right)_{2}$, разбавляли бидистиллированной водой до объема 10 мл и устанавливали содержание свинца и кадмия непламенным атомно-абсорбционным методом, в соответствии с изложенным в [6] по температурно-временной программе, приведенной в [1]. Одновременно одни и те же пробы анализировали атомно-абсорбционным стандартным методом после минерализации сухим и мокрым способами [1]. В качестве критерия полноты извлечения токсичных 
элементов использовали понятие степени извлечения, предложенное в [1].

Степень извлечения, определяли следующим образом:

$$
X=\frac{m}{n} \cdot 100, \%
$$

где $m$ - среднее арифметическое шести измерений содержания определяемого элемента по предлагаемому методу, мг/кг;

$$
n=(p+g) / 2, \mathrm{мг} / \mathrm{кг}
$$

где $p$ - среднее арифметическое шести измерений содержания определяемого элемента, полученное атомно-абсорбционным методом после сухого озоления, мг/кг [1];

$g$ - среднее арифметическое шести измерений содержания определяемого элемента, полученное атомно-абсорбционным методом после мокрой минерализации, мг/кг [6].

Результаты и обсуждение. В результате проведенных исследований установлено, что при использовании совместного действия УЗ высокой и низкой частот степень извлечения свинца и кадмия была несколько выше (98-99 \%), чем при использовании только одного низкочастотного У3 (93-96 \%) при проведении извлечения с использованием оптимальных окислителей, подобранных для каждого вида пищевого продукта (указаны выше в методиках проведения экспериментов) [4] (табл.1).

Таблица 1

\section{Степень извлечения свинца и кадмия из различных пищевых продуктов при совместном воздействии УЗ высоких и низких частот

\begin{tabular}{|c|c|c|c|c|}
\hline \multirow{3}{*}{$\begin{array}{c}\text { Наименование } \\
\text { пробы }\end{array}$} & \multicolumn{4}{|c|}{ Степень извлечения, \% } \\
\hline & \multicolumn{2}{|c|}{$\begin{array}{c}\text { Совместное действие УЗ высокой } \\
\text { и низкой частот }\end{array}$} & \multicolumn{2}{|c|}{ Низкочастотный УЗ } \\
\hline & Свинец & Кадмий & Свинец & Кадмий \\
\hline 1 & 2 & 3 & 4 & 5 \\
\hline Мясо (говядина) & 99 & 98 & 94 & 93 \\
\hline Мясо(свинина) & 99 & 98 & 95 & 93 \\
\hline Молоко, жирностью 2,5 \% & 99 & 99 & 96 & 95 \\
\hline Молоко, жирностью 3,2 \% & 99 & 99 & 95 & 93 \\
\hline Сливки жирностью10 \% & 99 & 98 & 93 & 94 \\
\hline Сливки жирностью20 \% & 98 & 98 & 93 & 95 \\
\hline Мука пшеничная, в/с & 99 & 98 & 93 & 93 \\
\hline Крупа перловая & 99 & 99 & 96 & 94 \\
\hline Крупа гречневая & 99 & 99 & 96 & 95 \\
\hline Хлеб «Донбасский новый» & 99 & 99 & 96 & 94 \\
\hline Булочка с повидлом & 98 & 99 & 97 & 95 \\
\hline Кофе растворимый & 98 & 99 & 95 & 96 \\
\hline Яблоки & 99 & 98 & 96 & 96 \\
\hline Капуста & 99 & 99 & 94 & 95 \\
\hline Сок абрикосовый & 98 & 98 & 96 & 95 \\
\hline Пиво Оболонь светлое & 98 & 98 & 95 & 96 \\
\hline Пиво Черниговское светлое & 99 & 98 & 94 & 96 \\
\hline
\end{tabular} и УЗ низкой частоты}

Примечание. В этой таблице и последующих представлены усредненные результаты шести опытов. Масса навески пищевого продукта - 1,00 г. Окислитель - пероксид водорода, количество - 5 мл. Параметры У3 при совместном воздействии: частота высокочастотного - 1 МГц, низкочастотного - 22 кГц, интенсивность

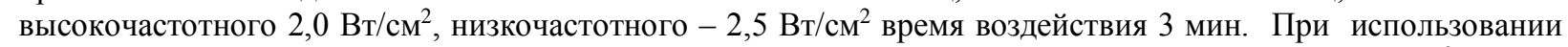
одного низкочастотного УЗ параметры были такими- частота -22 кГц, интенсивность-7 Вт/см², время воздействия 3 мин.

Изменение частоты низкочастотного УЗ от 18 до 47 кГц на величину степени извлечения влияния не оказывало, сравнение результатов полученных с использованием высокочастотного УЗ частотой 1 и 2 МГц показало, что лучшие результаты были получены в первом случае (табл. 2). 


\begin{tabular}{l|lr|ll|ll} 
& ISRA (India) & $=\mathbf{1 . 3 4 4}$ & SIS (USA) & $=\mathbf{0 . 9 1 2}$ & ICV (Poland) & $=\mathbf{6 . 6 3 0}$ \\
Impact Factor: & ISI (Dubai, UAE) $=\mathbf{0 . 8 2 9}$ & PUHL (Russia) $=\mathbf{0 . 2 0 7}$ & PIF (India) & $=\mathbf{1 . 9 4 0}$ \\
& GIF (Australia) & $=\mathbf{0 . 5 6 4}$ & ESJI (KZ) & $=4.102$ & IBI (India) & $=\mathbf{4 . 2 6 0}$ \\
& JIF & $=\mathbf{1 . 5 0 0}$ & SJIF (Morocco) & $=\mathbf{2 . 0 3 1}$ & & \\
\hline
\end{tabular}

Таблица 2.

Влияние частоты УЗ на степень извлечения свинца и кадмия

\begin{tabular}{|c|c|c|c|c|}
\hline \multirow{3}{*}{$\begin{array}{c}\text { Наименование } \\
\text { пробы }\end{array}$} & \multicolumn{4}{|c|}{ Степень извлечения, \% } \\
\hline & \multicolumn{2}{|c|}{$1 \mathrm{MГц}$} & \multicolumn{2}{|c|}{2 МГц } \\
\hline & Свинец & Кадмий & Свинец & Кадмий \\
\hline \multirow[t]{2}{*}{ Мясо (говядина) } & & & & \\
\hline & 100 & 98 & 92 & 93 \\
\hline Мясо(свинина) & 100 & 98 & 93 & 91 \\
\hline \multirow[t]{2}{*}{ Молоко, жирностью 2,5 \% } & & & & \\
\hline & 100 & 100 & 95 & 96 \\
\hline \multirow[t]{2}{*}{ Молоко, жирностью 3,2 \% } & & & & \\
\hline & 100 & 100 & 92 & 93 \\
\hline \multirow[t]{2}{*}{ Сливки жирностью10 \% } & & & & \\
\hline & 99 & 98 & 91 & 90 \\
\hline \multirow[t]{2}{*}{ Сливки жирностью20 \% } & & & & \\
\hline & 98 & 98 & 89 & 84 \\
\hline \multirow[t]{2}{*}{ Мука пшеничная, в/с } & & & & \\
\hline & 99 & 98 & 95 & 97 \\
\hline Крупа перловая & 100 & 100 & 94 & 95 \\
\hline \multirow[t]{2}{*}{ Крупа гречневая } & & & & \\
\hline & 100 & 100 & 95 & 93 \\
\hline \multirow[t]{2}{*}{ Хлеб «Донбасский новый» } & & & & \\
\hline & 100 & 100 & 97 & 95 \\
\hline \multirow[t]{2}{*}{ Булочка с повидлом } & & & & \\
\hline & 98 & 100 & 91 & 90 \\
\hline \multirow[t]{2}{*}{ Кофе растворимый } & & & & \\
\hline & 98 & 100 & 94 & 91 \\
\hline Яблоки & 99 & 98 & 92 & 92 \\
\hline Капуста & 100 & 99 & 95 & 94 \\
\hline \multirow[t]{2}{*}{ Сок абрикосовый } & & & & \\
\hline & 98 & 98 & 94 & 94 \\
\hline \multirow[t]{2}{*}{ Пиво Донецкое, 14\% } & & & & \\
\hline & 98 & 98 & 90 & 91 \\
\hline \multirow[t]{2}{*}{ Пиво Донецкое, 12\% } & & & & \\
\hline & 99 & 98 & 92 & 93 \\
\hline
\end{tabular}

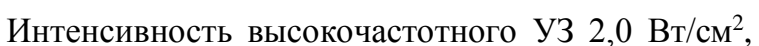
низкочастотного - $2,5 \mathrm{BT} / \mathrm{cm}^{2}$. Частота низкочастотно УЗ - 22 кГц. Время воздействия УЗ- 3 мин.

Оптимальная интенсивность высокочастотного УЗ и низкочастотного УЗ зависели от вида пищевого продукта и частоты высокочастотногоУЗ и не превышала $2,0 \mathrm{BT} / \mathrm{cm}^{2}$ для высокочастотного и $2,5 \quad \mathrm{BT} / \mathrm{cm}^{2}$ для низкочастотного (табл. 3).

Таблица 3.

\section{Величина оптимальной интенсивности УЗ в зависимости от вида пищевого продукта и частоты УЗ}

\begin{tabular}{|l|c|c|}
\hline \multicolumn{1}{|c|}{\begin{tabular}{c}
\multirow{1}{*}{$\begin{array}{c}\text { Наименование } \\
\text { пробы }\end{array}$} \\
\cline { 2 - 3 }
\end{tabular}} & \multicolumn{2}{|c|}{$\begin{array}{c}\text { Оптимальная интенсивность У3, } \\
\text { Вт/см }\end{array}$} \\
\hline Мясо(свинина) & 1,8 & 22 Гц \\
\hline $\begin{array}{l}\text { Молоко, жирностью } \\
2,5 \%\end{array}$ & 1,7 & 2,0 \\
\hline $\begin{array}{l}\text { Сливки } \\
\text { жирностью20\% }\end{array}$ & 2,0 & 2,0 \\
\hline Крупа гречневая & 1,5 & 1,8 \\
\hline
\end{tabular}




\begin{tabular}{|l|c|c|}
\hline Булочка с повидлом & 1,6 & 2,0 \\
\hline Кофе растворимый & 1,5 & 2,0 \\
\hline Яблоки & 1,6 & 1,5 \\
\hline Сок абрикосовый & 1,6 & 1,7 \\
\hline Пиво Донецкое, $14 \%$ & 1,8 & 2,0 \\
\hline
\end{tabular}

При этом, под оптимальной интенсивностью понимали такую интенсивность, которая обеспечивает достижение максимально возможной величины аналитического сигнала. Следует отметить, что оптимальная интенсивность при использовании только одного низкочастотного УЗ была значительно выше и составляла от $3,5 \mathrm{BT} / \mathrm{cm}^{2}$ для соков до $7 \mathrm{BT} / \mathrm{cm}^{2}-$ для молокопродуктов. Время воздействия двухчастотного УЗ должно быть не менее 1 мин для соков, 2 мин для продуктов растительного происхождения и 3 мин для продуктов животного происхождения при использовании в качестве окислителя пероксида водорода. Следует отметить, что даже при увеличении времени воздействия УЗ в 3 раза величина аналитического сигнала не изменялась. Порядок включения УЗ низкой и высокой частот на полученные результаты влияния практически не оказал.

Более высокая эффективность одновременного воздействия УЗ высокой и низкой частот объясняется особенностями образования и схлопывания кавитационных пузырьков при двухчастотном воздействии УЗ при котором преимущественно (более 90 \%) образуются малые сферические кавитационные пузырьки, при схлопывании которых наиболее эффективно интенсифицируются звукохимические реакции, лежащие в основе ускорения процессов минерализации [7].

Изменение частоты низкочастотного УЗ от 18 до 100 кГц на величину степени извлечения бета-кротина не оказало. Сравнение результатов, полученных с использованием высокочастотного У3 частотой 1-5 МГц показало, что лучшие результаты были получены при использовании У3 частотой 1,0-2,5 МГц (табл. 2). При этом интенсивность низкочастотного УЗ должна быть 1,5-2,5 Вт/см ${ }^{2}$, а высокочастотного - 2,5-4,0 $\mathrm{BT} / \mathrm{cm}^{2}$ (табл. 2). Время воздействия УЗ должно быть не менее 2 мин.

\section{Выводы.}

Таким образом, использование совместного действия УЗ высокой и низкой частот позволяет, по сравнению с использованием только низкочастотного УЗ, повысить степень извлечения, использовать один окислитель для всех пищевых продуктов, что позволяет создать унифицированную методику анализа пищевых продуктов. Более высокую интенсифицирующую способность совместного действия УЗ высокой и низкой частот, по сравнению с УЗ только одной низкой частоты, можно, очевидно, объяснить преобладанием в первом случае суммарной массы малых сферических пузырьков (способствуют протеканию звукохимических реакций) над большими деформационными (способствуют массообменным процессам, диспергирования, эмульгирования) [7]. Разработана унифицированная методика определения свинца и кадмия в различных пищевых продуктах. Правильность методики проверяли анализом одних и тех же проб стандартным методом (табл. 4).

Таблица 4.

Результаты определения свинца и кадмия в пищевых продуктах

\begin{tabular}{|l|c|c|c|c|c|c|c|c|}
\hline \multirow{3}{*}{ Наименование пробы } & \multicolumn{9}{|c|}{ Найдено, мг/кг; (n=6) } \\
\cline { 2 - 10 } & \multicolumn{3}{|c|}{ Предлагаемым методом } & \multicolumn{3}{c|}{ Стандартным методом [1] } \\
\cline { 2 - 10 } & $\mathrm{Pb}$ & $\mathrm{S}_{\mathrm{r}}$ & $\mathrm{Cd}$ & $\mathrm{S}_{\mathrm{r}}$ & $\mathrm{Pb}$ & $\mathrm{S}_{\mathrm{r}}$ & $\mathrm{Cd}$ & $\mathrm{S}_{\mathrm{r}}$ \\
\hline Мясо (свинина) & 0,195 & 0,06 & 0,037 & 0,08 & 0,192 & 0,09 & 0,035 & 0,10 \\
\hline Молоко, жирностью 2,5\% & 0,092 & 0,07 & 0,013 & 0,07 & 0,095 & 0,10 & 0,012 & 0,11 \\
\hline Молоко, жирностью 3,2 \% & 0,114 & 0,07 & 0,020 & 0,07 & 0,116 & 0,10 & 0,018 & 0,10 \\
\hline Сливки жирностью 10\% & 0,128 & 0,07 & 0,021 & 0,06 & 0,134 & 0,10 & 0,019 & 0,09 \\
\hline Сливки жирностью 20\% & 0,160 & 0,06 & 0,020 & 0,07 & 0,155 & 0,09 & 0,022 & 0,10 \\
\hline Крупа пшеничная, в/с & 0,150 & 0,07 & 0,014 & 0,08 & 0,153 & 0,10 & 0,013 & 0,09 \\
\hline Крупа перловая & 0,066 & 0,07 & 0,041 & 0,07 & 0,061 & 0,10 & 0,036 & 0,09 \\
\hline Крупа гречневая & 0,085 & 0,07 & 0,053 & 0,06 & 0,081 & 0,10 & 0,048 & 0,10 \\
\hline
\end{tabular}




\section{Impact Factor:}

\begin{tabular}{lr|lr} 
ISRA $($ India & $=\mathbf{1 . 3 4 4}$ & SIS $($ USA) & $=\mathbf{0 . 9 1 2}$ \\
ISI $($ Dubai, UAE) $=\mathbf{0 . 8 2 9}$ & PИНЦ (Russia) $=\mathbf{0 . 2 0 7}$ \\
GIF (Australia) $=\mathbf{0 . 5 6 4}$ & ESJI (KZ) & $=\mathbf{4 . 1 0 2}$ \\
JIF & $=\mathbf{1 . 5 0 0}$ & SJIF $($ Morocco $)=\mathbf{2 . 0 3 1}$
\end{tabular}

\begin{tabular}{|l|c|c|c|c|c|c|c|c|}
\hline Хлеб «Донбасский новый» & 0,159 & 0,08 & 0,035 & 0,08 & 0,153 & 0,10 & 0,030 & 0,11 \\
\hline Булочка с повидлом & 0,217 & 0,07 & 0,019 & 0,08 & 0,211 & 0,10 & 0,018 & 0,09 \\
\hline Кофе растворимый & 0,114 & 0,06 & 0,029 & 0,08 & 0,114 & 0,09 & 0,027 & 0,09 \\
\hline Яблоки & 0,157 & 0,06 & 0,014 & 0,08 & 0,153 & 0,09 & 0,012 & 0,10 \\
\hline Капуста & 0,084 & 0,07 & 0,007 & 0,08 & 0,085 & 0,09 & 0,008 & 0,10 \\
\hline Сок абрикосовый & 0,079 & 0,07 & 0,009 & 0,08 & 0,071 & 0,11 & 0,011 & 0,10 \\
\hline Пиво Черниговское, $14 \%$ & 0,129 & 0,07 & 0,019 & 0,08 & 0,122 & 0,09 & 0,021 & 0,10 \\
\hline
\end{tabular}

Примечание. При анализе продуктов по предлагаемой методике основные показатели были следующими. Масса навески пищевого продукта - 1,00 г. Окислитель - пероксид водорода, количество - 5 мл. Параметры УЗ при совместном воздействии: частота высокочастотного - 1 МГц, низкочастотного - 22 кГц,

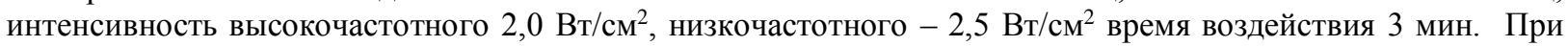
использовании одного низкочастотного УЗ параметры были такими- частота -22 кГц, интенсивность-7 Вт/см², время воздействия 3 мин.

Унифицированная методика определения свиниа и кадмия в пищевых продуктах растительного и животного происхождения.

Навеску продукта животного происхождения массой 0,50 г или растительного происхождения массой 1,00 г помещают в пробирку и приливают 5 мл пероксида водорода (90 \%). Пробирку помещают в магнитострикционный излучатель и воздействуют УЗ с частотой 22 кГц и 1 МГц с интенсивностью 2,0 и $2,5 \mathrm{BT} / \mathrm{cm}^{2}$ соответственно.
Время воздействия УЗ при анализе продуктов растительного происхождения 2 мин, а при анализе продуктов животного происхождения - 3 мин.

К полученному минерализату приливают 1 мл 0,01 мг/л раствора $\mathrm{Pd}\left(\mathrm{NO}_{3}\right)_{2}$, разбавляют бидистиллированной водой до объема 10 мл и устанавливают содержание свинца и кадмия непламенным атомно-абсорбционным методом по температурно-временной программе, приведенной в [3].

\section{References:}

1. (2012) Ul'trazvuk $\mathrm{v}$ analiticheskoy khimii i tekhnologicheskoy tekhnologii: monografiya /A.N. Baklanov, A.P. Avdeyenko, S.A. Konovalova $\mathrm{t}$ L.V. Baklanova.- Kramatorsk: DGMA, 2012.- 332 p.

2. Yurchenko O. I. (2015) Intensifikatsiya sukhoy mineralizatsii pishchevykh produktov parami okisliteley s IK-oblucheniyem / O.I. Yurchenko, A.N. Baklanov, Ye.A. Belova, O.S. Kalinenko, L.V. Baklanova, V.I. Larin // Ukraïns'kiy khímíchniy zhurnal. - 2015. - T. 81, № 4. - p. 98-102.

3. Yurchenko O.I. (2015) Ul'trazvuk dlya intensifikatsii sukhogo mineralizatsii pishchi okislitelyami v paroobrazovanii / Oleg Ivanovich Yurchenko, Aleksandr Nikolayevich Baklanov, Kalinenko Ol'ga Sergeyevna, Yelena Aleksandrovna Belova, Larisa Vladimirovna Baklanova // Mezhdunarodnyy nauchnyy zhurnal «Teoreticheskiye i prikladnyye nauki». Razdel 9. Khimiya i khimicheskaya tekhnologiya. - 2015. - № 7 (27). - p. 122-129.
4. Yurchenko O.I. (2016) Ul'trazvuk v opredelenii svintsa, medi i kadmiyumina sakhara i produktov na yego osnove / O.I. Yurchenko A.N. Baklanov, O.S. Kalinenko Ye.A. Belova L.V. Baklanova // Mezhdunarodnyy nauchnyy zhurnal «Teoreticheskiye i prikladnyye nauki. Razdel 9. Khimiya i khimicheskaya tekhnologiya. - 2016. - № 1 (33). - p. 158-163.

5. Baklanov A.N., Chmilenko F.A. (2001) Ispol'zovaniye vysokochastotnogo ul'trazvuka $\mathrm{v}$ sonolyuminestsentnoy spektrofotometrii. Usileniye analiticheskogo signala // Izvestiya vuzov. Khimiya i khimicheskaya tekhnologiya.

6. (1986) GOST 26927-GOST 26935 - 86 Syr'ye i produkty pishchevyye. Metody opredeleniya toksichnykh elementov. M .: Gos.komitet SSSR po standartam.-1986.- 85 p.

7. Margulis M.A. (1986) Zvukokhimicheskiye reaktsii i sonolyuminestsentsiya.-M.: Khimiya, 1986.-288 p. 